\title{
Commentary: Spam in a can
}

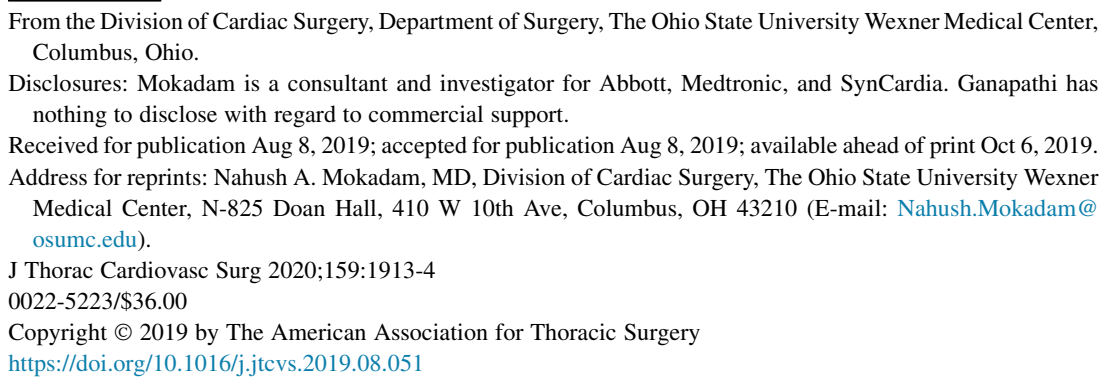

From the Division of Cardiac Surgery, Department of Surgery, The Ohio State University Wexner Medical Center, Columbus, Ohio.

Disclosures: Mokadam is a consultant and investigator for Abbott, Medtronic, and SynCardia. Ganapathi has nothing to disclose with regard to commercial support.

Received for publication Aug 8, 2019; accepted for publication Aug 8, 2019; available ahead of print Oct 6, 2019 Address for reprints: Nahush A. Mokadam, MD, Division of Cardiac Surgery, The Ohio State University Wexner Medical Center, N-825 Doan Hall, 410 W 10th Ave, Columbus, OH 43210 (E-mail: Nahush.Mokadam@ osumc.edu).

J Thorac Cardiovasc Surg 2020;159:1913-4 $0022-5223 / \$ 36.00$

Copyright (C) 2019 by The American Association for Thoracic Surgery

https://doi.org/10.1016/j.jtcvs.2019.08.051

The moon landing-considered one of humankind's defining achievements, with this year of 2019 marking the 50th anniversary of the best of the best. In the infancy of Project Mercury (America's first space project), however, space exploration was not perceived to be a pinnacle of success, but rather quite the opposite. As noted in the New Journalism classic The Right Stuff, "The commanding officer at Edwards [Airforce Base] passed the word around that he wanted his top boys, the test pilots in Fighter Ops, to avoid Project Mercury because it would be a ridiculous waste of talent; they would just become 'Spam in a Can.", ${ }^{1}$ Similarly it is likely that many young medical students hear analogous comments about cardiothoracic surgery. "Why do you want to waste your career and talent?" and "Don't you ever want to see your family?" are just a few heard during medical school for more than 20 years. Notably, these comments can serve as a significant exposure for students, yet they never come from cardiothoracic surgeons, but instead from those with little contact with the field. Indeed, there is now a nationwide workforce shortage, which will only get worse before (if ever) it gets better.

In this issue of the Journal, Coyan and colleagues ${ }^{3}$ discuss a survey-based study examining medical student perceptions toward cardiothoracic surgery, both as a career and the field as a whole. Given the shortage in the workforce of cardiothoracic surgeons, Coyan and colleagues ${ }^{3}$ attempted to ascertain when and why medical students lost interest in cardiothoracic surgery. According to this survey, the main deterrent to pursuing a career in cardiothoracic surgery came from a lack of exposure, coupled with a perception of a poor lifestyle. They therefore concluded that the earlier exposure may lead to increased opportunities for recruitment of cardiothoracic surgeons. In the article, they describe actions implemented at their own institution to increase exposure and interest in cardiothoracic surgery.

There is a shortage both of cardiothoracic surgeons and of physicians as a whole. We as a community must continue

\section{References} 824-9.

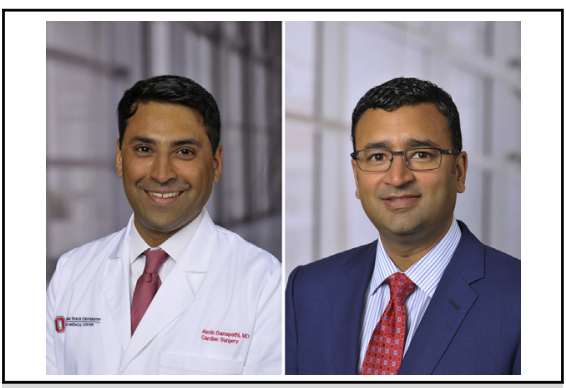

Asvin M. Ganapathi, MD (left), and Nahush A. Mokadam, MD (right)

\section{Central Message}

Cardiothoracic surgeons must engage and mentor students early and often throughout medical school to prevent the loss of exceptional candidates.

See Article page 1906.

to focus on recruiting the best and the brightest students while correctly portraying our field and countering false perceptions. As suggested, we can accomplish this by earlier exposure, coupled with strong mentorship. Although many foundational scholarship opportunities exist for students, such as the Society of Thoracic Surgeons Looking to the Future Scholarship and the American Association for Thoracic Surgery Member for a Day, our mentorship must neither begin nor end with these annual opportunities. Rather, our real opportunity exists in working with medical students early and consistently throughout medical school, whether through didactics (eg, chest anatomy, cardiopulmonary physiology, and related pathophysiology), interest groups, or experiences in the operating room, as has been suggested for neurosurgery and orthopedic surgery. ${ }^{4,5}$ By engaging students earlier and more often, we can demonstrate how we affect our patients, our true lifestyle choices, our focus on gender inclusion, and the constant innovation present in our field. We must control the narrative of what it is truly like to be a cardiothoracic surgeon so that we will attract and retain exceptional candidates. "Spam in a can" maybe to some, but without it, we would never be able to reach for the moon.

1. Wolfe T. The Right Stuff. New York: Bantam Books; 1979.

2. Moffatt-Bruce S, Crestanello J, Way DP, Williams TE Jr. Providing cardiothoracic services in 2035: signs of trouble ahead. J Thorac Cardiovasc Surg. 2018;155: 
3. Coyan GN, Kilic A, Gleason TG, Schuchert MJ, Luketich JD, Okusanya O, et al. Medical student perceptions of a career in cardiothoracic surgery: results of an institutional survey. J Thorac Cardiovasc Surg. 2020;159: 1906-12.
4. O'Connor MI. Medical school experiences shape women students' interest in orthopaedic surgery. Clin Orthop Relat Res. 2016;474:1967-72.

5. Quintana LM. Recruitment of medical students into neurosurgery: some strategies. World Neurosurg. 2013;80:789-91. 